\title{
Ontologia e Poética Visual no espetáculo ADAM's PASSION, DE ROBERT WILSON
}

\author{
ONTOLOGY AND VISUAL PoETICS IN THE SPECTACLE \\ ADAM'S PASSION, BY ROBERT WILSON
}

\author{
Klara Cruz de Oliveira* \\ Luciane Viana Barros Páscoa **
}

\section{RESUMO}

O artista Robert Wilson é uma importante figura para o teatro contemporâneo, pois seus espetáculos teatrais são compostos de uma virtuosa visualidade, que se constitui em metáforas e signos que precisam ser decodificados pelo espectador de acordo com sua observação perante a obra. Com base em sua trajetória artística e pessoal é que percebemos a construção da identidade cênica e a maneira que são concebidas suas obras. Uma das formas de enunciação poética do artista acontece através da liberdade dada ao fruidor para experimentá-la, fazendo com que seus espetáculos sejam um conjunto de espectros de paisagens a serem elucidadas pelo próprio observador. Devido a isso, para adentrarmos em questões ontológicas evocadas pela visualidade do artista, é necessário que contextualizemos alguns relatos de sua trajetória pessoal. Essa foi uma das principais instâncias que fizeram com que questões conceituais fossem exploradas cenicamente por esse diretor teatral ao longo dos anos. Portanto, para que afunilemos este estudo, iremos visualizar os caminhos da narrativa do personagem bíblico Adão, no espetáculo Adam's Passion. Ademais, nossos materiais metodológicos para esta investigação se imbricam nos pensamentos de ontologia da arte, concatenados por Currie (1989), e pela abordagem da análise de espetáculos de Belém (2014).

Palavras-chave: Robert Wilson. Adam’s Passion. Análise de espetáculos. Ontologia da Arte. Teatro Contemporâneo.

\begin{abstract}
The artist Robert Wilson is an important character to contemporary theater, as his theatrical performances are composed by virtuous visuality, which is reproduced in metaphors and signs that need to be unraveled by the viewers according to their observation about the work. Being from his artistic and personal trajectory that we perceive the construction of his scenic identity, and also the way his works are conceived. For one of the artist's forms of poetic enunciation happens through the freedom given to the audience to experience it, making his performances a set of the spectrum of landscapes to be elucidated by the work's observer. Because of this, in order to enter into ontological issues evoked by the artist's visuality, it is necessary that we go through triggers arising from his personal life, as this was one of the main instances that caused conceptual issues to be explored scenically by this theatrical director over the years. Therefore, for us to funnel this study, we will visualize the paths of the narrative of the biblical character Adam, in the show

\footnotetext{
* Bacharel em Teatro pela Universidade do Estado do Amazonas (2018). Mestranda do Programa de PósGraduação em Letras e Artes (UEA) e bolsista da Fundação de Amparo à Pesquisa do Estado do Amazonas. Brasil. ORCID: 0000-0002-2995-2377. E-mail: klaraoliveirac@gmail.com.

** Doutora em História pela Universidade do Porto (2006). Mestre em História pela Pontifícia Universidade Católica de São Paulo (1997). Professora adjunta da Universidade do Estado do Amazonas. Professora do Programa de Pós-Graduação em Letras e Artes (PPGLA-UEA). Brasil. ORCID: 0000-0001-7751-0189. Email: luciane.pascoa@gmail.com.
} 
Adam's Passion. Furthermore, our methodological materials for this investigation are intertwined in the thoughts of art ontology, concatenated by Currie (1989), and also in the path indicated by the analysis of spectacles approach, by Belém (2014).

Keywords: Robert Wilson. Adam's Passion. Spectacle Analysis. Art Ontology. Contemporary Theatre.

\section{INTRODUÇÃO}

Estreada em 2015 na Estônia, possuindo por volta de uma hora e meia de duração, o espetáculo Adam's Passion é dirigido por Robert Wilson ${ }^{1}$ e dispõe como diretor musical o compositor Arvo Pärt² - que na obra utilizou sua composição Adam's Lament como inspiração para a criação da trilha sonora do espetáculo. Porém, para que cheguemos em especificidades referentes a essa obra teatral, devemos percorrer a trajetória pessoal do encenador, para que, enfim, possamos entender uma possível perspectiva de como houve a diacronicidade que consistiu questões subjetivas que contribuíssem para a concepção visual da peça.

Desse modo, trazemos análises que podem ser realizadas com base na visualidade apresentada no espetáculo Adam's Passion. Ressalta-se que essa é apenas uma possibilidade de interpretação da obra do encenador. Para isso, nessa primeira parte do artigo nos ampararemos pela corrente pós-positivista, pois essa “[...] não tentará predizer um fenômeno ou buscar leis gerais. O paradigma pós-positivista/qualitativo postula a existência de múltiplas construções da realidade segundo os pontos de vista dos pesquisadores [...]" (FORTIN; GOSSELIN, 2014, p. 3).

Ainda nessa definição, percebe-se que o pós-positivismo abarca a ontologia como uma das ramificações de seu conjunto de ferramentas para a realização de pesquisas em arte, sobretudo quando se trata de influências na vida pessoal do artista, que possivelmente refletiram em sua arte. Na observação de leis ontológicas, nota-se que nos referimos a uma “[...] realidade subjetiva e múltipla. A realidade não é algo à parte do pesquisador [...]” (FORTIN; GOSSELIN, 2014, p. 5).

Sendo assim, Wilson, nascido na cidade do Texas, é um dos principais responsáveis por reformular a cena teatral contemporânea. Ao longo de seus 58 anos de carreira, o encenador experimentou diversas práticas artísticas - que vão desde aulas de balé à

\footnotetext{
${ }^{1}$ Robert Wilson (1941 - atual), nascido na cidade do Texas, foi responsável por pensar a cena contemporânea pelo viés visual, fazendo disso uma característica intrínseca de suas obras. (GALIZIA, 2004)

2 Arvo Pärt (1935 - atual) é um músico contemporâneo nascido na Estônia, pertencente à corrente artística intitulada minimalismo. (ARVO, 2015b)
} 
construção de site-specifics, como consequência do contato com as mais diversas manifestações de arte. Essas determinaram sua forma de pensar e conduzir as encenações, além de atribuir à visualidade cênica de suas obras características deslumbrantemente plásticas e sinestésicas, que passaram a ser uma particularidade intrínseca de seus espetáculos.

Isso ocorre por Wilson pensar que a criação cênica não deveria se limitar ao texto dramático para estabelecer uma troca de experiência com o espectador, mas que essa fruição deveria acontecer principalmente pela visualidade estética da cena. Dessa forma, os processos de criação do encenador são motivados pela exploração da exuberância visual na encenação, combinando e recombinando símbolos, signos, formas, cores e tamanhos, de forma que até os atores são considerados elementos visuais dentro da cena. Portanto, no teatro realizado por esse diretor, há a ruptura de uma estrutura do molde da tríade aristotélica. O espetáculo não possui uma narrativa de começo, meio e fim, mas um conjunto de objetos associativos, que conduzem os fruidores a adentrarem ao mundo proposto dentro da peça.

Desse ponto, percebemos que esse artista desencadeia processos de atribuição de sentidos múltiplos a uma infinidade de elementos para a concretização do universo a ser proposto em suas obras, como é o caso de Adão, em Adam's Passion, uma figura bíblica presente no inconsciente coletivo, conhecida universalmente por diversas pessoas de religiões distintas. Do ponto de vista ontológico, Krause (2017, p. 93) aponta essa liberdade associativa como uma forma de conceber leis que serão de origem lógica ao espectador:

Aceitamos que a lógica tem relevância ontológica, mas de que tipo? A resposta pode estar em que tipo de concepção se aceita para as origens das leis lógicas. Pensamos [...] que a lógica tradicional tem origem em nossa concepção imediata de mundo, do mundo que nos cerca. Esse mundo é, cremos que para a maioria das pessoas que partilham conosco o mesmo background cultural, composto de objetos. Nosso mundo é um mundo de coisas que exibem aos nossos sentidos "múltiplos atributos ou propriedades". (KRAUSE, 2017, p. 93)

Essa característica presente nas obras de Wilson faz com que o espectador seja instigado a todo o momento a tornar-se ávido a respeito das informações que está recebendo, sendo levado à reflexão por meio da sinestesia oriunda dos elementos compostos na cena, que se chocarão ou se completarão em relação ao próprio quadro cênico. A completude de conjuntos visuais colocados na encenação possui o objetivo de causar um frisson individual em cada fruidor. Porém, esses desencadeamentos associativos e individualizados de uma possível leitura da obra teatral estão cerceados por elementos que darão margem para que a fruição de cada indivíduo não alcance voos que ultrapassem esse 
universo criado, mas que o explorem ao máximo. Nesse jogo de sentidos levantados pelo encenador "[...] tais objetos são indivíduos, no sentido em que podem ser identificados, receber nomes, serem contados, discernidos de outros, etc”. (KRAUSE, 2017, p. 94).

No caso de Adam's Passion, os elementos fruitivos pensados pelo diretor para esse espetáculo conduzem o espectador a adentrar a narrativa do personagem dos textos de valor sagrado ao cristianismo, desde o nome da obra-até os signos cênicos colocados no palco. Portanto, essas subjetividades da visualidade da encenação dão margem dentro do universo bíblico, que é inspiração da origem a obra, a um enorme campo para a fruição do sujeito que a ela assiste. Desse modo, deixa-se a cargo do fruidor restringir-se a observar o espetáculo apenas do viés narrativo literal da história ou, então, contextualizá-la com base em reflexões atuais, que podem ir desde aspectos patriarcais que figuras do gênero masculino representam em nossa sociedade à dimensões teológicas, as quais perpassam pela relação entre o homem e divindades criadoras, pois, nessa perspectiva, vê-se a representação de Adão como um apanhado de possíveis signos que se diacronizam com discussões contemporâneas, como ilustra George (2012, p. 10):

Adão foi feito para usufruir de um relacionamento exclusivo e pessoal com seu Criador. Com essa relação, o primeiro homem se diferenciaria claramente do resto da criação. Em sua vida racional, Adão seria como Deus no que se refere a possuir razão, vontade, intelecto e emoções. Do lado moral, ele refletiria o Criador em bondade e pureza, ou seja, seria o homem perfeito. Contudo, como um ser criado, Adão também poderia achar-se suscetível à tentação. (GEORGE, 2012, p. 10)

Mediante isso, o entoar das subjetividades apresentadas eleva-se ao ponto inicial de que as fronteiras imaginativas devem cercear os caminhos fruitivos da peça. Sendo assim, percebe-se que Wilson potencializa os aspectos sígnicos no espetáculo, de modo que esses sejam responsáveis pela narrativa, visto que a dramaturgia textual não se faz presente. Desse modo, Krause (2017, p. 94) afirma que, "Em outras palavras, tais objetos são indivíduos, no sentido em que podem ser identificados, receber nomes, serem contados, discernidos de outros, etc. Este é, aliás, um dos postulados mais básicos que assumimos para a eficácia de nosso discurso.” (KRAUSE, 2017, p. 94).

Entretanto, para que se observe a obra do encenador de forma aprofundada do ponto de vista ontológico, é necessário primeiramente que tomemos como base os atravessamentos pessoais que ecoaram na construção identitária da visualidade desse diretor teatral. Delineiam-se os traços constituintes que levaram o encenador a utilizar seus espetáculos como paisagens visuais que influenciam figuras e seres característicos que fazem parte da história humana ou da imaginação coletiva, como já realizara com Albert Einstein, 
Sigmund Freud, Orfeu, entre outros. Portanto, a compreensão do processo de um fenômeno é o ponto crucial para procurarmos as pistas da subjetividade palpável, que ilustra a materialidade visual dos espetáculos desse artista, como aponta Heidegger (2002, p. 204):

$\mathrm{Na}$ compreensão, a presença projeta seu ser para possibilidades. Esse ser para possibilidades, constitutivo da compreensão, é um poder-ser que repercute sobre a presença as possibilidades enquanto aberturas. $\mathrm{O}$ projetar da compreensão possui a possibilidade própria de se elaborar formas. (HEIDEGGER, 2002, p. 204).

\section{OS ATRAVESSAMENTOS PESSOAIS COMO PARTE DA CONSTRUÇÃo IDENTITÁRIA DA VISUALIDADE NAS OBRAS DE WILSON}

Wilson adquiriu a peculiar estética plástica junto à grandiosidade estrutural de suas obras, ao não se identificar com o teatro que era feito na década de 6o, sendo assim, o artista tomou um caminho oposto ao que se estabelecia no circuito norte-americano da época. A busca pelo virtuosismo estético em suas obras possuía como consequência altos custos de produção, porém o encenador não abria mão de apresentar um espetáculo grandioso, como colocado por ele mesmo:

Eu odiava o teatro na década de 60. O que eu fazia não parecia com o que o Living Theatre, Open Theatre ou Performance Group estava fazendo. Eu ia contra tudo isso que faziam. Eu detestava aquela estética teatral. Eu tinha mais em comum com o teatro do século XIX e com as vaudevilles, do que com esses grupos. Eu era formalista. Eu utilizava a arquitetura do proscênio. Meu teatro era em caixa cênica, e eu tratava o público com delicadeza. Quando grande parte de Nova York estava indo para o minimalismo, eu estava fazendo peças ricas e barrocas, como Stalin e Deafman Glance. (WILSON apud HOLMBERG, 2005, p. 3, tradução nossa) ${ }^{3}$.

O artista originário da cidade do Texas, logo ao terminar a graduação em arquitetura e urbanismo, mudou-se para a cidade de Nova York, que à época concentrava as inovações na cena artística com o surgimento de novas diversas expressões de arte. Entre elas estava o que posteriormente viria a ser denominado happening. ${ }^{4}$ Estando intimamente ligado ao acaso e ao momento efêmero, os happenings geralmente eram apresentados em locais urbanos, e Wilson via nessa expressão novas possibilidades para a criação cênica. Segundo

\footnotetext{
3 "I hated the theatre in the 6o's. I was never part of that movement. What I was doing did not resemble the Living theatre, the Open theatre, or the Performance group. I went against everything they were doing, I loathed the way their theatre looked. I had more in common with 19th century theatre and vaudeville than with these groups. I was formalistic. I used the proscenium arch. My theatre was interior and I treated the audience with courtesy. When New York was going for minimalism in a big way, I was doing rich, baroque pieces like Stalin and Deafman Glance.” (WILSON apud HOLMBERG, 2005, p. 3).

4 Happening é uma expressão artística em que os elementos principais para sua execução consistem na efemeridade e espontaneidade, pois, uma vez apresentado, nunca mais se repetirá. (PAVIS, 2008).
} 
Galizia (2004, p. XXIII), "Wilson identificou-se imediatamente com a possibilidade do uso do acaso e da improvisação como meios de se atingir resultados artísticos”.

Além disso, nota-se que seu interesse por manifestações de arte contemporâneas aparece explícito em suas peças, pois são observadas as noções dilatadas de temporalidade dentro de cena - em alguns casos, uma simples caminhada dura mais de uma hora; o texto, quando dito, é feito de forma fragmentada ou inserido como uma paisagem sonora ao ser emitido pelos atores; outro ponto são as lacunas deixadas em aberto nas narrativas dos espetáculos, especialmente em Adam's Passion.

Dessa forma, percebe-se que essas circunstâncias fomentaram o projeto poético do artista, esclarecendo a maneira de expressar sua visão de mundo por meio da estética que suas criações possuem, como afirma Salles (2006, p. 38): "O projeto poético está também ligado a princípios éticos de seu criador: seu plano de valores e sua forma de representar o mundo. Pode-se falar de um projeto ético caminhando lado a lado com grande propósito estético do artista [...]".

Esculpindo ainda mais o que chamamos aqui de projeto poético, identifica-se que esse elemento se faz um dos pilares para que possamos tentar compreender o modo de criação, bem como a familiaridade do artista com os fenômenos que o envolvem. Nessa perspectiva, fica esclarecido que a busca por possíveis compreensões da forma de apreensão do artista para com o mundo faz com que consigamos adentrar caminhos que nos levem a tentar descobrir suas singularidades, sobretudo se estivermos em busca de respostas para as suas criações. Posto isso, Salles (2006, p. 37) reconhece que mediante essa característica que “[...] estamos, portanto, no campo da unicidade de cada indivíduo. São gostos e crenças que regem o seu modo de ação: um projeto pessoal, singular e único [...]”.

Portanto, em uma perspectiva ontológica na compreensão da formação dos traços que definem e redefinem as escolhas estéticas de Wilson e, principalmente, suas concepções artísticas, percebemos que a conjuntura que se estabelece perante a emolduração de suas criações ao longo de sua trajetória foi fundamentada nos atravessamentos pessoais que marcaram a sua vida ainda na fase de se autocompreender como artista cênico.

Vemos que é “[...] a partir da significância aberta na compreensão de mundo que o ser da ocupação com o manual se dá a compreender, qualquer que seja a conjuntura que possa estabelecer com o que lhe vêm ao encontro [...]” (HEIDEGGER, 2002, p. 205). Sendo assim, faz-se necessário observar como a trajetória de vida desse encenador corroborou para que esses acontecimentos fossem refletidos em sua arte, e principalmente em Adam's Passion. 
Além dos fatores sociais, houve duas figuras que foram de suma importância para entendermos os caminhos traçados por Wilson até a forma visual cristalizada em Adam's Passion. Uma delas foi uma criança surda chamada Raymond Andrews. A situação que proporcionou o encontro de ambos aconteceu de forma cruel, pois, de acordo com Pinheiro (2017), o diretor teatral viu o menino, que na época tinha por volta de 12 anos de idade, sendo agredido por um policial e, então, percebeu que o menor, ao receber questionamentos, não respondia com palavras, mas emitia sons incomuns. A criança vinha de uma classe desfavorecida e era incompreendida pelos familiares, que não demonstravam empatia com sua condição, pois pretendiam interná-la no reformatório. Foi então que o encenador resolveu adotar Andrews, fazendo com que o garoto ficasse sob sua tutela.

A segunda criança apadrinhada pelo artista norte-americano foi Christopher Knowles, que na época de seu encontro com Wilson tinha por volta dos 14 anos de idade. Logo cedo recebendo o diagnóstico de possuir Transtorno de Espectro Autista, o menino possuía uma habilidade de decompor palavras, criar sonoridade com elas, de modo que parecessem paisagens sonoras, construir leitmotivs com a voz e fazer de seu vocábulo um arcabouço matemático de comunicação, pois essa era a forma que ele se comunicava, devido à decorrência de sua condição de TEA. Mediante os fatos narrados, Galizia (2004, p. 27) ilustra de forma breve o acontecido fatídico que atravessaria a vida e ambos os artistas:

Knowles era então considerado uma criança autista e frequentava uma escola especial ao norte de Nova Iorque. Quando Knowles veio visitar a família durante o natal, Klauber 5 apresentou-o a Wilson, que convidou-o a participar de uma cena de $A$ vida e época de Joseph Stalin. Isto foi em 1973, quando Knowles tinha 14 anos de idade. Após este primeiro contato, Wilson conseguiu a tutela do menino e começou a tratá-lo como um artista, ao invés de um autista. (GALIZIA, 2004, p. 27)

Ao ouvir a habilidade do pequeno em utilizar as palavras de forma singular, o encenador pediu para que Knowles contribuísse com suas criações. Então, essa união trouxe benefícios a ambas as partes, pois, enquanto o diretor ressignificava seu trabalho cênico, a criança tinha consideráveis avanços devido ao seu contato com o fazer artístico. Esse encontro fez com que o menino saísse da clínica que visava tentar remover sua condição em alguma medida, pois "[...] Knowles estava em uma instituição para crianças com danos cerebrais, a O. D. Heck School, e todos ali presentes tentavam consertá-lo, fazer com que escrevesse e falasse da forma correta [...]” (PINHEIRO, 2017, p. 92). Entretanto, o contato

\footnotetext{
5 George Klauber é amigo de Wilson, ocupando também as funções de artista plástico e professor. (GALIZIA, 2004).
} 
com o artista norte-americano abriu portas para que o até então pré-adolescente pudesse experimentar e se expressar livremente de forma poética e desprendida de qualquer julgamento social, como apontado Pinheiro (2017, p. 92): "Wilson não via Knowles (tal qual Raymond Andrews) como um deficiente - que precisava ser normalizado a qualquer custo - mas um indivíduo cuja habilidades e percepções eram únicas”.

Na magnitude de nortear um artista pela sua inserção em um determinado contexto vivido, torna-se presunçoso enclausurá-lo a apenas um determinado fenômeno em específico. Dessa forma, entende-se que não apenas uma, mas várias experiências que permearam a trajetória de vida de Wilson, desde sua saída do Texas até o contato com as crianças que viriam ser adotadas pelo encenador, tornaram-se partes de um grande paradigma norteador, potencializando o modo de expressão como o artista se vê inserido no mundo. Tais questões parecem estar implícitas em Adam's Passion, visto que a narrativa de Adão carrega aspectos atemporais que dialogam com a noção de sujeito e sua ambivalência no mundo contemporâneo, como apontado por Feiler (2019, p. 17):

Adão e Eva ainda importam porque capturam o que continua sendo uma verdade fundamental sobre estar vivo: nossa maior ameaça como indivíduos é nos sentirmos excluídos, isolados, amedrontados, sozinhos; nossa maior ameaça como sociedade é sucumbir a forças semelhantes de desunião, desarmonia, medo, ódio. [...] por quaisquer critérios nossas conversas diárias são dominadas por ansiedade e confusão sobre o risco de desconexão e distanciamento, sobre o desafio de manter fortes laços sociais; sobre preocupações com a deterioração de nosso tecido social. (FEILER, 2019, p. 17)

Desse ponto, é importante observar nuances e subjetividades que o impacto relacional do artista-sujeito para com acontecimentos experienciados puderam ser deliberados em forma de criação teatral. Nessa característica, podemos evocar o pensamento de Langer (2011, p. 262) ao afirmar que “[...] toda obra de arte tem algo sobre o qual pode dizer que provém do mundo e que evidencia o próprio sentimento do artista acerca da vida”. Dessa maneira, compreendemos que Adam's Passion pode conter os aspectos narrativos do personagem bíblico Adão, mas também o reflexo da imersão de Wilson nesse macrocosmos que o envolveu desde o início de sua carreira artística, levando-o à construção de apontamentos contemporâneos e utilizando como pano de fundo essa narrativa cristã. Desse modo, Langer (2011, p. 262) retorna afirmando que “[...] somos impelidos à simbolização e articulação do sentimento que temos de compreendê-lo a fim de nos mantermos orientados na sociedade e na natureza”.

Sendo assim, percebemos que essa não é a primeira direção do encenador norteamericano em que a narrativa cênica é oriunda de um tema sacro. Em 2007, no Théâtre du 
Châtelet, em Paris na França, o diretor teatral dirigiu o espetáculo Saint John Passion, ${ }^{6}$ que possuiu como trilha sonora a peça homônima de Johann Sebastian Bach.7 Desse modo, podemos observar que o encenador possui alguns enlaces com figuras do universo cristão, podendo-se deixar em aberto duas possibilidades para esses acontecimentos permearem o catálogo de criações do artista: as inquietudes advindas de sua religiosidade ou o impacto histórico-social que essas narrativas míticas possuem em alguma medida nos tempos atuais.

\subsection{A poética visual em Adam's Passion}

Sendo assim, observa-se que Wilson realiza peças que se desprendem de um possível consenso do entendimento por parte de todos dos espectadores, levando-os a buscar liberdade em desenvolver suas próprias leituras de formas distintas. Portanto, para que nos aprofundemos em questões conceituais que envolvem o espectador e a poética religiosa presente em Adam's Passion, iremos utilizar da configuração de análise dos espetáculos postulada por Sally Banes em sua obra Writing Dancing in the Age of Postmodernism (BANES, 1994) - que, apesar de ser pensada para a dança, pode ser facilmente contextualizada na arte teatral. Nesse esquema é necessário que ocorram quatro etapas para que se coloque em prática o método, sendo elas a descrição, interpretação, avaliação e explicação contextual, entretanto, as duas últimas serão explicitadas quando fizermos o apanhado geral das neologias levantadas ao longo de toda essa pesquisa. Deste modo, Belém (2014, p. 4) melhor exemplifica esses pontos:

A descrição teria como foco o quê os dançarinos fizeram e sobre o quê o trabalho parece ser. A interpretação mostraria o quê o trabalho comunicou e o quê a dança significa. A avaliação seria realizada em torno da relevância e qualidade do trabalho. A explicação contextual deveria mostrar de onde o trabalho deriva estética e historicamente. (BELÉM, 2014, p. 4)

Na figura 1, por exemplo, poderíamos classificar o clarão que corta o ciclorama, como a presença do ser divino, nomeado pela cultura cristã como Deus. Devido a existirem várias menções na bíblia em que a materialidade desse ser mítico é referenciada como uma divindade iluminada (e mais perto das partículas físicas que conhecemos como luz), em uma

\footnotetext{
${ }^{6}$ A paixão segundo São João.

7 Johann Sebastian Bach (1685, Eisenach - 1750, Leipzig) foi compositor e organista. Considerado o membro mais importante da família Bach, seu gênio combinou uma excelente performance musical com poderes criativos, domínio técnico e controle intelectual perfeitamente equilibrados. Sua obra lhe rendeu uma posição histórica única. Sua linguagem musical era distinta e extraordinariamente variada, reunindo e superando as técnicas, os estilos e as realizações gerais de sua geração e das gerações anteriores, e levando a novas perspectivas. (WOLFF; EMERY, 2001).
} 
das passagens da bíblia observa-se a ressonância referida à metáfora aqui mencionada: “Deus é luz, e não há nele trevas nenhumas. [...] se andarmos na luz como ele está, temos comunhão uns com os outros" (Jo 1, 5-7)8. Portanto, percebendo a presença onírica do deus reverenciado pelos cristãos, essa forma o presentifica na obra ao mesmo tempo que omite sua faceta, preservando aqui essa característica que perdura em grande parte das narrativas que referenciam a divindade.

Figura 1 - Cena inicial do espetáculo Adam's Passion

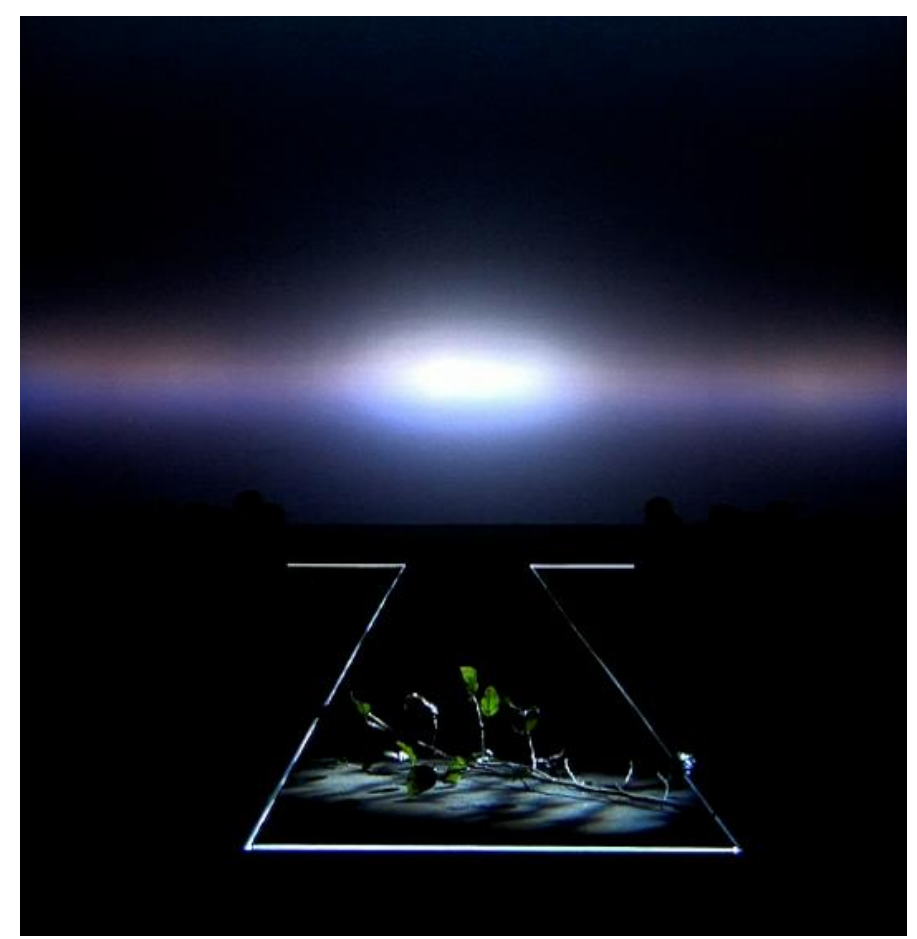

Fonte: Adam's Passion - DVD (ARVO, 2015a)

Desse modo, poderíamos classificar o primeiro momento cênico como uma metáfora para os primeiros versículos do livro Gênesis, presentes na Bíblia Sagrada, por ser nesse recorte do escrito em que há a criação de céu terra, separação entre luz e escuridão, a criação de flores, folhas e frutos. Para tanto, observa-se um código visual na encenação que evoca a noção de infinitude celestial e espaço terreno, tanto pela representação do clarão que corta o ciclorama ao fundo, como o arbusto presente no início da passarela que faz parte do palco. No antagonismo de representativos visuais presentes na caixa cênica, observa-se que a perspectiva medial do quadro de cena se encontra vazio, por ser interstício entre essas duas figuras sígnicas que a representatividade humana se encontra presentificada, como relata Nissa (2017, p. 34) ao trazer o pensamento de que "[...] sendo o céu e a terra diametralmente

\footnotetext{
${ }^{8}$ Todas as referências da Bíblia desse trabalho foram tomadas de BÍBLIA, (2010).
} 
opostos entre si por causa das suas atividades, a criação, que está no meio, em parte participa das situações vizinhas e se coloca no meio dos extremos [...]”.

Portanto, a simbologia desse recorte cênico perpassa por leituras que vão ao encontro de que a criação da existência surgiu a partir de um choque de forças que ora são antagônicas, ora corroboram para um mesmo mote e, consequentemente, acontece a gênese da força geradora. É nesse embate de impulsos constituintes entre o movimento e o repouso que pode vir a acontecer de originar novos possíveis fenômenos, como afirmado por Nissa (2017, p. 33): “Julgo que o grande Moisés, declarando que, no princípio, Deus criou o céu e a terra, desejasse significar que, na criação, todos os fenômenos que por vontade de Deus, foram conduzidos à geração se originaram do movimento e do repouso”.

Sendo assim, percebe-se que essa característica de análise vem ao encontro do pensamento de Currie (1989, p. 41) ao dizer que “[...] apreciar uma imagem exige não que apenas avaliemos os elementos que compõem sua aparência [...], requer que vejamos os elementos visíveis da imagem como evidências de outras coisas”. Desse ponto de vista, percebemos que Wilson abre possibilidades para que a ontologia seja empregada nessa criação específica, pois os aspectos visuais presentes na peça são os principais meios comunicacionais na obra, junto ao título que dá nome à encenação. Eles nos permitem adentrar em leituras que perpassam não apenas pelo paradigma de uma visualidade puramente descritiva dos elementos sígnicos presentes no espetáculo, mas que também vão além disso.

Ademais, no mesmo quadro de cena, percebemos a presença do arbusto com folhas ainda em seu estado de vida. Nessa configuração, podemos pensar o galho com folhagens, como uma representação poética do jardim do Éden, onde o personagem bíblico Adão morou no início da história narrada no livro Gênesis: “[...] plantou o Senhor Deus um jardim do éden, [...] e pôs ali o homem que tinha formado. E o senhor Deus fez brotar da terra toda a árvore agradável à vista e boa para comida, e a árvore da vida [...], e a árvore da ciência do bem e do mal" (Gn 2, 8-9). Trazendo a ideia de que a construção cênica da obra é em grande parte baseada nos mitos narrados na mitologia judaico-cristã, observamos que o encenador subverte as noções simbólicas ao introduzir de forma metafórica possíveis elementos característicos que fazem parte da estória que envolve a narrativa do personagem Adão.

$\mathrm{Na}$ busca da compreensão de elementos ambíguos postulados pelo encenador, principalmente no que se refere às pistas eclesiásticas colocadas na formulação do simbolismo cênico em Adam's Passion, associamos uma compreensão sensível de que pode acontecer de alguns aspectos de fruição visual da peça sejam apenas apreendidos por traços 
subjetivos da cognição, de modo que realizar uma descrição sobre a obra, limita as possibilidades de interpretação. Entretanto, ressalta-se que em nossa análise oferecemos alguns questionamentos que podem ser realizados em uma ótica mais aprofundada acerca das ambiguidades do espetáculo, portanto, a partir dessa postulação Heidegger (2002, p. 235) emite o juízo de que "[...] essa ambiguidade oferece a curiosidade o que ela busca e confere ao falatório a aparência de que nele tudo se decide".

\section{Figura 2 - Possível representação do personagem Adão, em Adam's Passion}

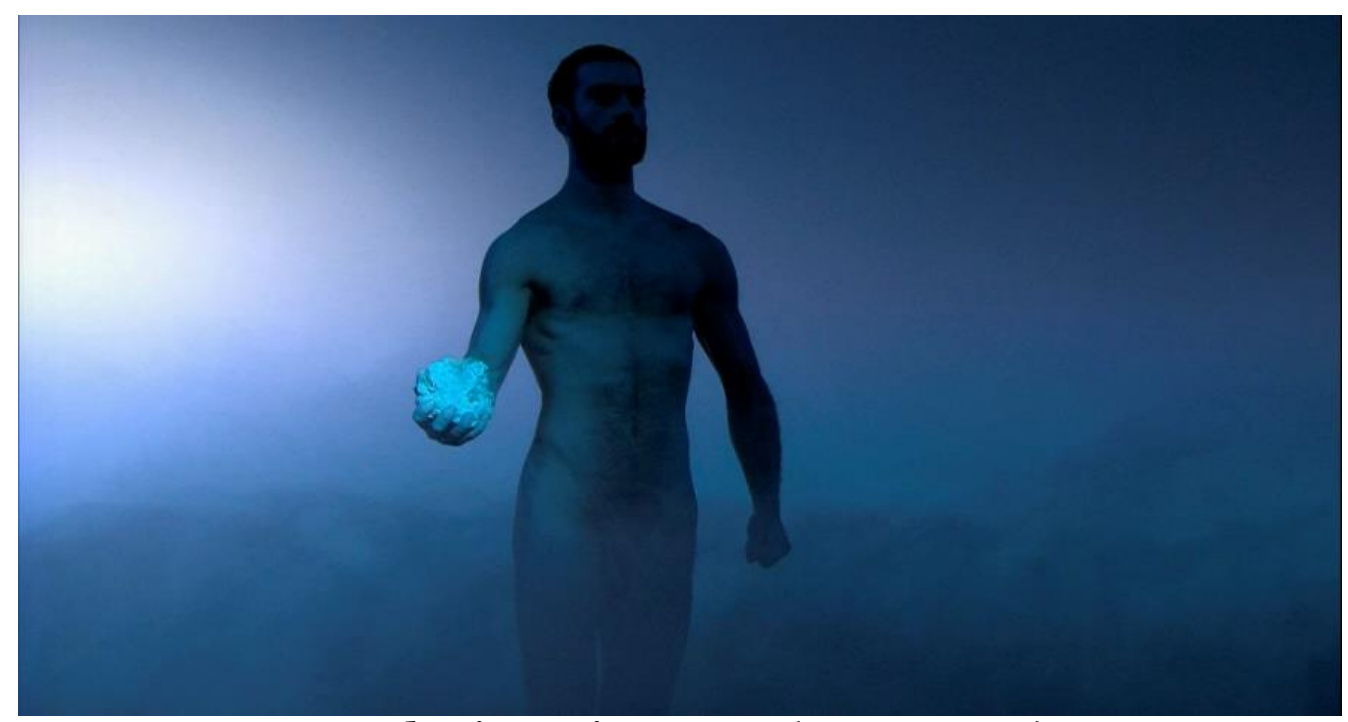

Fonte: Adam's Passion - DVD (ARVO, 2015a)

Desse modo, na figura 2, percebemos a possível representação de Adão no espetáculo. Apesar de estar classificado apenas como um homem, no programa da peça, alguns fatores nos evocam a ideia desse ator ser a imagem do personagem bíblico, tanto por esse artista ser o protagonista da obra e a única figura do gênero masculino com um grande destaque na encenação, como por fatores simbólicos que conduzem a narrativa dessa figura ao longo da peça.

Dentre os simbolismos mais significativos pertencentes a esse ator está o pedaço de rocha carregado nas suas mãos. Observando que esse elemento natural é um unívoco no campo do cristianismo com grande impacto no protestantismo e ortodoxia, geralmente está ligado à referência da criação do primeiro ser vivente no universo, que no glossário bíblico é conhecido por Adão, como vemos na passagem a seguir: "E formou o senhor deus o homem do pó da terra, e soprou em seus narizes o fôlego da vida" (Gn 2, 7). A forte metáfora simbólica da pedra pode ser lida também a partir de questões conceituais de acordo com o aprofundamento religioso de cada um, que tão melhor pode aprofundar apreciação dos espectadores, postulando simbolicamente referências bíblicas que os norteiam a criar 
possíveis narrativas ao espetáculo, como também ajudam a fortalecer nosso ponto de vista nesse estudo, do ator em questão ser a representação de Adão.

Consequentemente, mediante essas características, observamos que ao longo da história o símbolo da pedra foi familiarizado como uma peça que transcende o homem enquanto ser físico, conduzindo-o a uma espécie de retorno aos braços de entidades celestiais, como apontado por Chevalier (1986, p. 828, tradução nossa) ilustrando nesse sentido que as relações entre "[...] a pedra e o homem apresentam um duplo movimento de subida e descida. O homem nasce de Deus e retorna a Deus, a pedra bruta descende do céu, se transmuta e eleva-se de volta a ele [...]9" - quase como uma metáfora da ideia de retorno ao mundo espiritual. Além dessas subjetividades do objeto simbólico carregado pelo personagem, é perceptível que o ator de Adam’s Passion se faz completamente desnudo, fazendo alusão aos períodos do jardim do Éden em que não havia dissociação entre um corpo nu e um corpo vestido, pois naquele recorte temporal não haviam predisposições de julgamentos ou consciência da noção dúbia do termo maldade, ao contrário dos tempos atuais, em que se considera por grande parte da onda conservadora e retrógrada como algo completamente inusitado, principalmente quando relacionado aos campos da arte.

Mediante isso, ainda se observa que já nesse ponto do espetáculo o pano de fundo possui uma coloração azul esplendorosa, semelhante ao céu. Desse modo, é possível observar que a atmosfera das obras de Wilson é propiciada sobretudo pela maneira transitória que a luz se encontra presente ao longo da encenação, comunicando aos espectadores paisagens, lugares ou até mesmo subjetividades próprias de questões pessoais dos personagens em cena. No caso de Adam's Passion, observamos que esse efeito cênico possui como objetivo principal trazer um clima etéreo ao palco, ajudando a construir com as tonalidades de azul um espaço com uma aura angelical e divina. É essa a maneira com que o encenador sistematiza a iluminação em seu teatro, como explicitado por Camargo (2012, p. 66):

A luz possibilita construir as formas no espaço, alterando-as continuamente. Não são as palavras, diz ele, que dão vida ao teatro, mas o espaço, cuja construção é possível ver por meio da luz. Outros diretores leem o teatro por intermédio do texto; Wilson o lê por intermédio da luz. "Eu sempre começo com a luz. Sem luz não há espaço. Um espaço diferente é uma realidade diferente." (CAMARGO, 2012, p. 66)

\footnotetext{
9 "La piedra y el hombre presentan un doble movimiento de subida y de bajada. El hombre nace de Dios y retorna a Dios. La piedra bruta desciende del cielo; transmudada, se eleva hacia él.” (CHEVALIER, 1986, p. 828).
} 


\section{Figura 3 - Adão, o fruto proibido e o pecado}

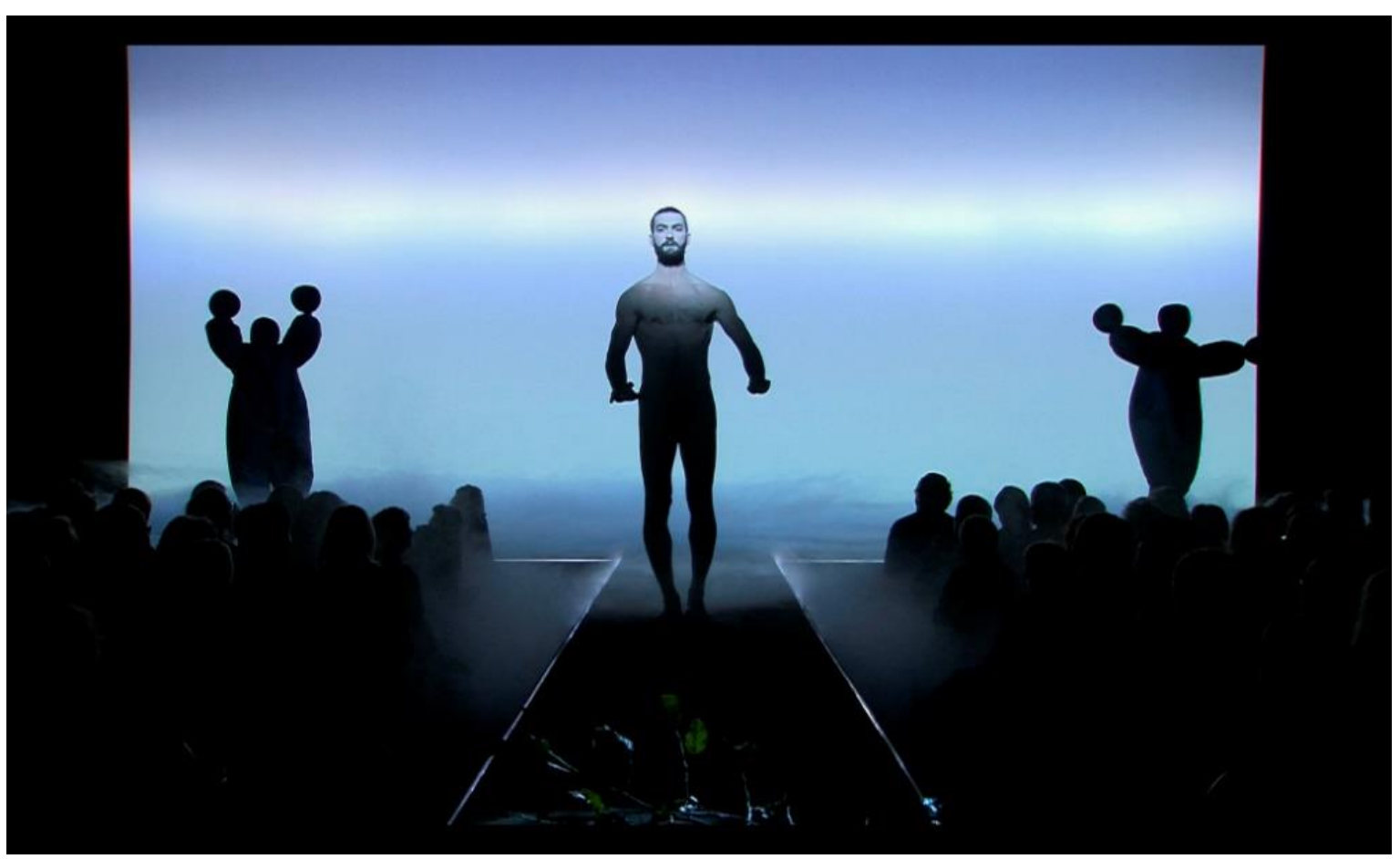

Fonte: Adam's Passion - DVD (ARVO, 2015a)

O deslumbre da tonalidade de azul que toma conta do palco é intenso, trazendo um aspecto pueril à encenação, bem como se fazia o jardim do Éden antes da ingestão do fruto do pecado. Entretanto, na figura 3, vemos que a configuração triádica em que a cena se apresenta nos enlaça subjetivamente ao momento narrativo em que ocorre o consumo humano do fruto proibido.

Algumas noções simbólicas podem ser aplicadas a esse recorte da narrativa de modo que ao meio vemos aquele que seria Adão, à sua frente um arbusto - que por sua vez poderia vir a ser retratado como a representação de árvores e, ao fundo, nas extremidades vemos atores trajando um figurino esteticamente esférico. Como se tem conhecimento, grande parte das frutas consumíveis se fazem geometricamente desse mesmo formato. Além disso, corroborando ainda mais com o pensamento, nesse exato momento da encenação, os mesmos realizam movimentações extremamente fortes, como se estivessem em um possível combate. Além disso, o volume da orquestra ao fundo aumenta de forma intensa, trazendo essa tensão ao recorte cênico. Na dubiedade da encenação, trazemos os escritos de Nissa (2017, p. 16), que ilustram sintomaticamente a metáfora da ingestão do fruto e sua relação com a preconização do temor causado:

Ele colocou o homem no Paraíso para colher o fruto da árvore da vida - esta árvore de todo bem, que é a posse de Deus mesmo. Mas o olhar do homem se desviou, deixando-se atrair 
pela árvore portadora do fruto promíscuo e cujo fim é a morte. A partir do momento em que se come este fruto que conduz à morte, o homem vagueia longe da imagem. (NISSA, 2017, p. 16)

Após o momento retratado na figura 3, a encenação muda completamente de ambientação, o azul antes radiante, agora se torna mais fúnebre. Sabe-se que na narrativa bíblica foi após a ingestão do fruto proibido que cruéis consequências aconteceram, pois agora conscientes da capacidade humana em cometer pecados e, sabendo do discernimento entre bem e mal, acarretou-se a expulsão de Adão e sua mulher do jardim paradisíaco. Na passagem a seguir isso fica extremamente evidente ao afirmar que, após Eva ingerir o fruto, deu-lhe a Adão que também o comeu, e "então foram abertos os olhos de ambos, e conheceram que estavam nus; coseram folhas de figueira e fizeram para si aventais" (Gn 3, 7).

Seguindo o enredo cênico, na figura 4, já temos o resultado da ingestão do fruto proibido e todas as suas consequências para a humanidade. Podemos descrever esse ato como um período de transição, em que vemos a dubiedade da face humana, entre o homem livre de características pecaminosas e aquele que agora possui discernimento entre a benevolência e maldade, não mais amparado por uma estrutura divina provedora do bemestar da condição da raça dos homens. Dessa maneira, percebemos que ao fundo do palco temos o ator que representa Adão e ao lado oposto uma criança - agora trajando vestimentas bem mais contemporâneas. Seria essa uma metáfora acerca das gerações futuras originadas pelo primeiro ser morador da terra, e a derivação que seu ato bíblico gerou ao longo da história? O compositor que contribuiu com a trilha sonora desse espetáculo aponta algumas pistas que nos fazem chegar a essa hipótese ao afirmar que "nós temos um link direto com Adão, nós talvez não sejamos a figura exata dele, mas ainda possuímos fragmentos dessa catástrofe cósmica" (ARVO, 2015b, tradução nossa) ${ }^{10}$.

O simbolismo dessa cena em relação à interligação da figura de Adão com a humanidade contemporânea se faz extremamente potente, pois disso se observa que as duas figuras são separadas no palco pela árvore do fruto proibido, que agora não mais possui folhagens, como sua simbolização no início do espetáculo. Além disso, os galhos se apresentam invertidos, sendo que “[...] tradicionalmente a imagem da árvore invertida, [...] significa que o ser humano está voltado à face espiritual e em oposição aos instintos animais

\footnotetext{
10 "We have a direct link to Adam. We may not have an exact picture of it, how it really was but it was a cosmic catastrophe.” (ARVO, 2015b)
} 
[...]” (CARROL; PASQUINELLI, 2018, p. 136, tradução nossa) ${ }^{11}$. Portanto, observamos que a forte metaforização desse quadro cênico provoca no espectador a noção de atemporalidade que a obra cênica carrega, não apenas alçando olhares a um mito histórico, mas também introduzindo-o com mesclas de discussões atuais, como apontado por Carrol e Pasquinelli (2018, p. 133, tradução nossa): “[...] a figura da árvore é apenas um espelho do ser humano e através da inversão de seus ramos, discernimos a sociedade de seu tempo"12.

\section{Figura 4 - A dualidade após a ingestão do fruto proibido}

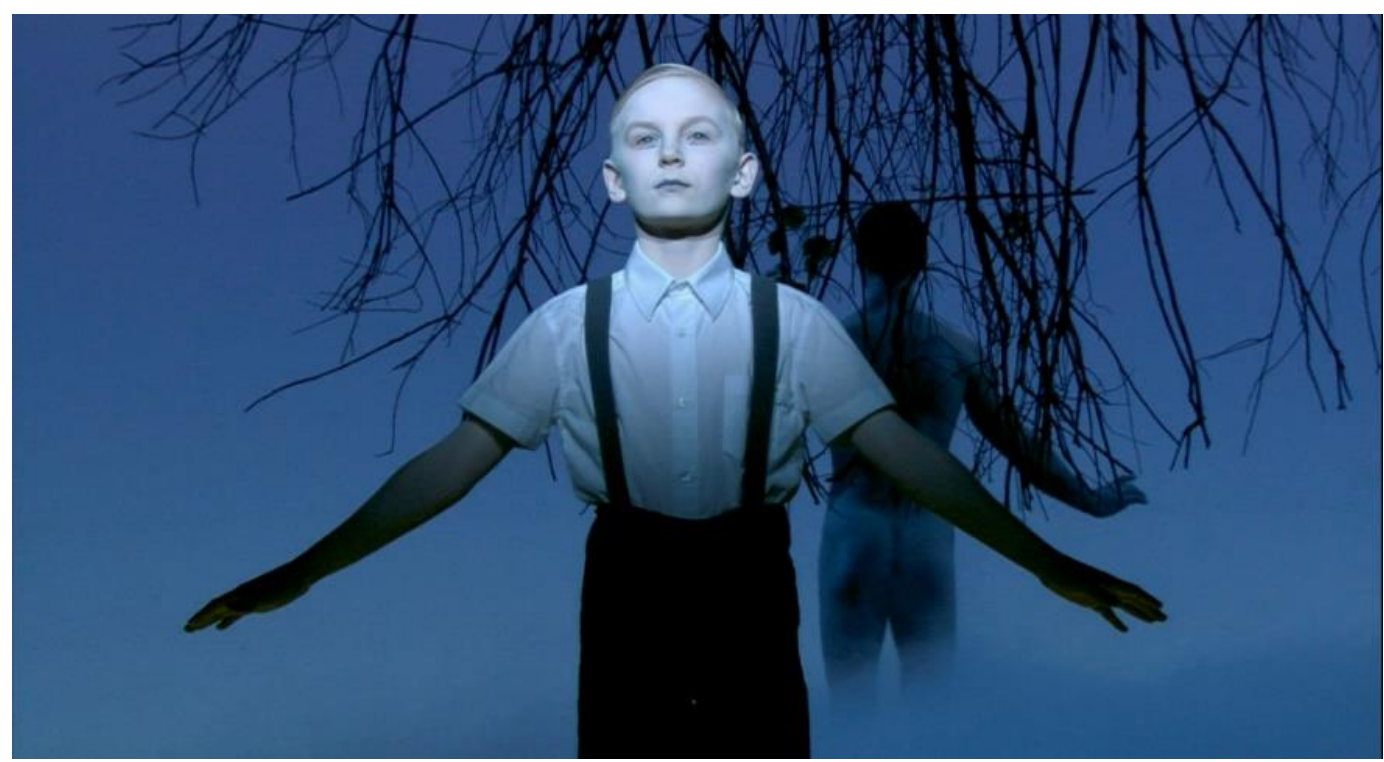

Fonte: Adam's Passion - DVD (ARVO, 2015a)

Após a cena em que ocorre a transição, a criança continua no palco, dessa vez manuseando blocos de concreto, como notamos na figura 5. Se alçarmos o olhar na condução da narrativa bíblica, após a ingestão do fruto que não deveria ser comido, há não somente a consciência entre bem e mal, mas também a expulsão dos seres humanos do jardim do Éden, que por sua vez agora precisam lutar pela sua própria sobrevivência: “[...] o senhor Deus, pois, o lançou para fora do jardim do Éden, para lavrar a terra de que fora tomado” (Gn 3, 17).

O simbolismo nessa cena poderia ser classificado como uma ramificação das gerações sucedentes a Adão ao longo da história, pois se leva em conta o contexto que o garoto aparece no espetáculo - como representação de uma nova geração, dentro da virada da narrativa

\footnotetext{
11 " [...] Traditionally the image of the inverted tree, [...] signifies that the human is projected towards the spiritual in opposition to the instinct of beasts [...]." (CARROL; PASQUINELLI, 2018, p. 136).

12 "[...] the tree figure is but a mirror of the human and through the inversion of its branches we discern the society of its time." (CARROL; Pasquinelli, 2018, p. 133).
} 
teatral - que ainda assim foi oriunda de erros acometidos por antepassados históricos. Nesse caso, os desvios incansavelmente se perdurarão por toda a eternidade, quase como se a pedra fosse a simbolização do peso a ser carregado por todos os descendentes dos primeiros seres humanos da terra, de acordo com o pensamento cristão. Desse modo, trazemos Chevalier (1986, p. 828, tradução nossa) para ilustrar esse pensamento, apontando que “[...] a pedra como elemento da construção, está ligada ao sedentarismo dos povos, a uma espécie de cristalização cíclica. Desempenhando um papel importante nas relações entre céu e terra"13. Entretanto, isso não retira seu caráter de também ser uma metáfora para a transformação, pois na bíblia cristã, a rocha também é remoldada a modo de se tornar pão, como bem lembrado por Chevalier (1986, p. 829, tradução nossa): “[...] sem dúvida há de se relacionar este símbolo com a transformação, como foi o caso bíblico com a transformação das pedras em pão"14.

\section{Figura 5 - O destrono entre a realidade concreta no Jardim do Éden}

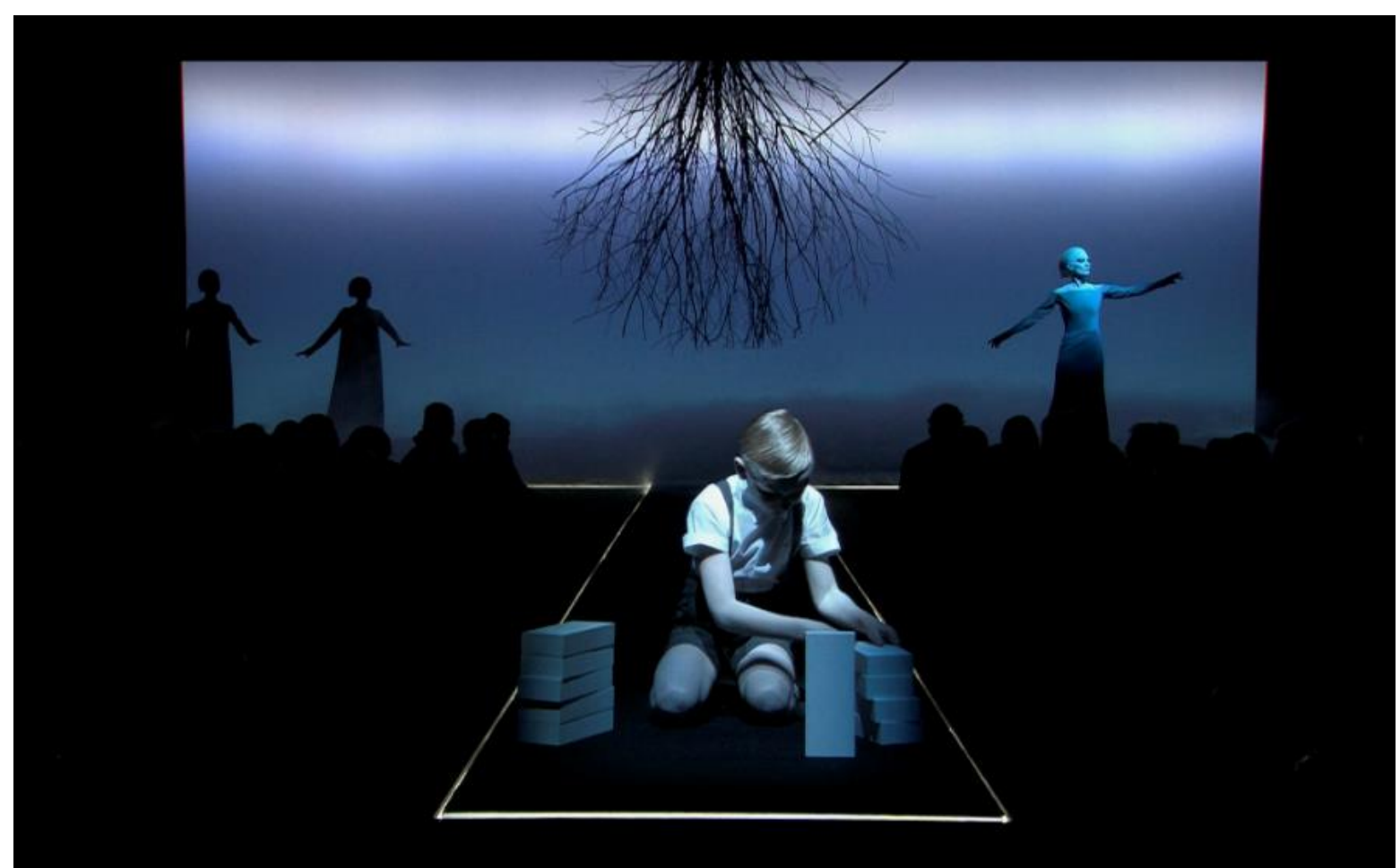

Fonte: Adam's Passion - DVD (ARVO, 2015a)

\footnotetext{
13 " “...] la piedra, como elemento de la construcción, está ligada a la sedentarización de los pueblos y a una especie de cristalización cíclica. Desempeña un papel importante en las relaciones entre el cielo y la tierra." (CHEVALIER, 1986, p. 828).

14 "[...] $\sin$ duda hay que relacionar este símbolo con la transformación de las piedras en pan de la que habla el Evangelio.” (CHEVALIER, 1986, p. 829).
} 
A ideia de transitoriedade entre as gerações e como a ação de Adão afligiu os povos de todas as nações de acordo com essa narrativa são os elementos mais notáveis nesse espetáculo. $\mathrm{O}$ ato em que o garoto se faz presente como protagonista no palco se encerra, e em sua saída vemos novamente um ato em que, agora uma figura mais velha percorre o quadro cênico em posse de um arbusto. Portanto, ao alçar a abertura para que o arbusto se faça um elemento que tem a mesma função de um fio de Ariadne ao longo da encenação, observamos que o encenador cada vez mais afunila os sentidos da peça a modo de provocar o espectador a tomar a narrativa para si, e não mais observá-la apenas como um arcabouço de imagens visuais puramente voltadas à virtuosidade.

Portanto, nesse efeito cíclico imbricado na encenação pelo diretor, por meio de nuances subjetivas e metafóricas, levantam-se discussões que atravessam a noção de temporalidade, bem como de problemas hereditários que trespassam gerações em uma perspectiva que não prevê finalização. Sabe-se que de maneira implícita podemos contextualizar o simbolismo presente em Adam's Passion a problemas sociais que não são consequentes das gerações atuais, entretanto, a elas assolam - e a todos que neste espaçotempo vivem. Para tanto, Mannheim (2010, p. 1952) afirma que:

Cada momento de tempo é propriamente um escopo temporal que possui várias dimensões, de modo que sempre é acessado a partir da diversidade das implantações de cada um dos estratos geracionais específicos que estão presentes. Portanto, o pensamento do tempo também deve ser organizado à força, polifonicamente - utilizando uma metáfora musical em cada momento de tempo é necessário que se escute as próprias vozes das gerações particulares surgem a cada período. (MANNHEIM, 2010, p. 1952)

\section{Figura 6 - As similitudes com a figura de Adão}

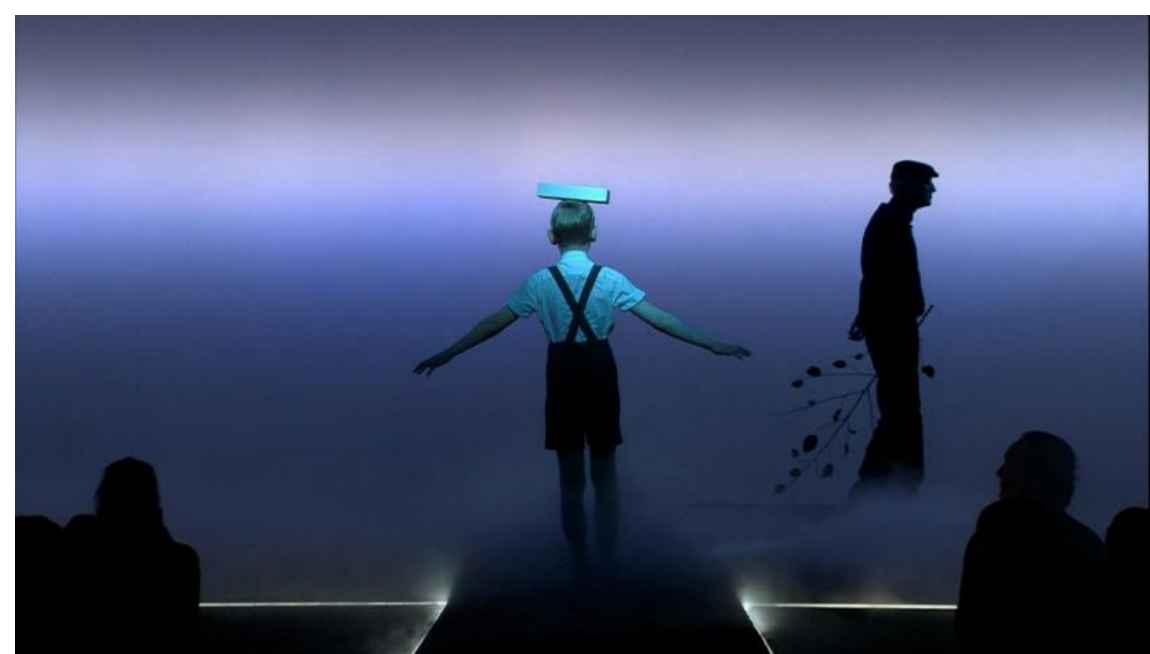

Fonte: Adam's Passion - DVD (ARVO, 2015a)

Na cena final de Adam's Passion, Adão retorna ao palco, agora usando vestes em cor 
preta, assim como as outras figuras que fizeram parte da composição do espetáculo ao longo de sua duração. Isso proporciona não mais uma sequência cênica fragmentada de acordo com o momento pensado para cada sujeito, como aconteceu ao longo de toda a peça até ali. Além disso, percebe-se a presença de vários outros rostos ocupando o palco, carregando um arbusto semelhante ao do início do espetáculo, e as roupas acompanham a mesma estética da usada pelo protagonista.

Desse modo, observa-se que o momento final figura como um encontro de personas que compuseram a obra, quebrando a noção de espaço-tempo construída ao longo da narrativa e apontando um possível anacronismo que ocorre durante toda a peça. Fazendo a harmonia com a narrativa bíblica, que evoca um sentido espiritual da relação entre o homem e uma figura demiúrgica, e um sentido mais terreno, demonstra que a força geradora que move a humanidade tem o poder de fazer com que fragilidades plantadas em tempos remotos assolem até mesmo gerações que perpassam nossas noções de entendimento. É como se a peça afirmasse subjetivamente em seu discurso teatral que o mito de Adão ainda possui encadeamentos atuais e se faz implícito na vida do sujeito contemporâneo, não sendo apenas a mitologia de cunho teológico. Pela perspectiva das noções filosóficas de tempo, Heidegger (2002, p. 47) nos comunica que

[...] o ser só pode ser compreendido, sempre e cada vez, na perspectiva e com referência ao tempo, também a resposta à questão do ser não pode ser dada numa sentença isolada e cega. A resposta não será apreendida nem compreendida se não se fizer mais do que repetir a sua formulação sentencial e, sobretudo, se ficar circulando de mão em mão como um resultado solto no ar de que se toma conhecimento como um ponto de vista e uma posição, talvez divergente da maneira tradicional de tratar. (HEIDEGGER, 2002, p. 47)

Figura 7 - Ato final do espetáculo Adam's Passion

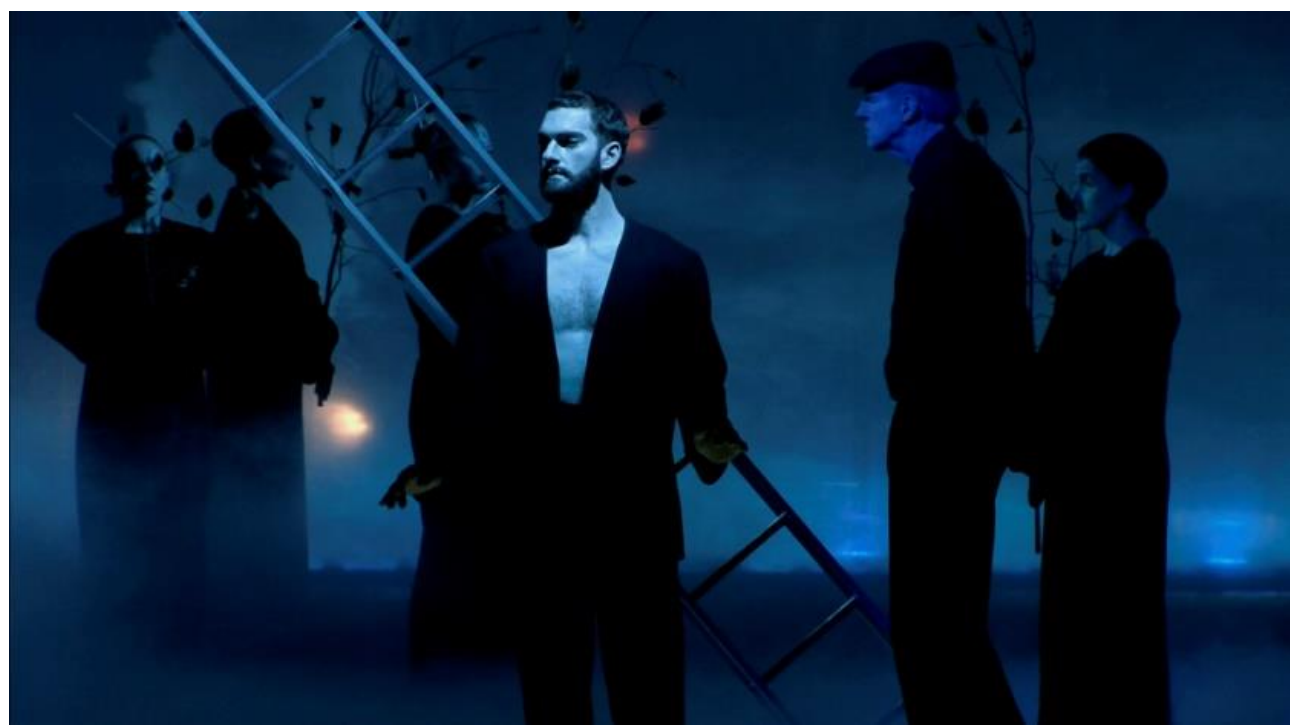

Fonte: Adam's Passion - DVD (ARVO, 2015a) 


\section{CONSIDERAÇõES FINAIS}

Debruçando-nos sobre a trajetória artística de Wilson, observamos que aspectos ontológicos podem ser analisados em sua concepção artística, tanto se levarmos em conta as singularidades pessoais que atravessaram sua jornada e refletiram em sua arte, como também sua peculiar característica em realizar a exploração visual do seu teatro. Devido ao fato de que, embora suas obras sejam potentes no virtuosismo e visualidade, elas possuem uma imensa carga de questionamentos e discursos implícitos, que podem vir à tona ou não, de acordo com a apreciação daquele que os assiste.

Nesse caso, trouxemos para discussão a obra Adam's Passion, que tem como pilar principal o mito bíblico do personagem Adão. Observamos que o encenador teatral utiliza essa narrativa para retratá-lo teatralmente, mas também busca levantar possíveis indagações voltadas aos tempos atuais. Portanto, vimos que explorar possíveis caminhos para as leituras sobre o espetáculo aqui citado, utilizando como base tópicos ontológicos, poderia nos levar a diversos nortes de discussão. No entanto, apenas lançamos luz sobre alguns pontos específicos, deixando em aberto para que cada indivíduo enfocasse seu olhar no que lhe fez mais característico. Desse modo, relembramos das falas de Currie (1989, p. 68) ao gentilmente afirmar que:

Eu gostaria de assumir a essência dessa ideia para nosso trabalho de analisar obras artísticas, apesar de modificações que acontecerão ao longo do processo. Para a nossa discussão anterior deixou-se claro que a apreciação de uma obra de arte não é meramente a apreciação de um produto final - um visual padrão, uma sequência de palavras e sons mas uma apreciação da realização do artista em chegar a esse padrão ou estrutura. A tarefa do crítico é nos ajudar a apreciar os trabalhos, e também é em partes nos ajudar a ver e experienciar coisas no padrão ou sequência que não poderia ser apreendida por nós. (CURRIE, 1989, p. 68)

Portanto, utilizar do discurso teatral para abordar questões que à primeira vista se limitam apenas a compreensão de elementos visuais não nos ajuda a aprofundar pontos de vista que iniciam com a visualidade, mas vão para além dela. Assim, observamos que a potência do discurso subjetivo que pode ser extraído de paisagens visuais, como é o caso das obras teatrais de Wilson, são elementos fundamentais para instigar a apreciação e provocar questionamentos nos fruidores de qualquer linguagem artística. 


\section{REFERÊNCIAS}

ARVO Pärt l - Adam's Passion. Direção: Robert Wilson. Produção: Kristjan-Jaak Nuudi. Tällin: Accentus Music, 2015a. 1 DVD. 1h36min.

ARVO Pärt l - The Lost Paradise. Direção: Günter Atteln. Produção: Kristjan-Jaak Nuudi. Tällin: Accentus Music, 2015b. 1 DVD. 5 min.

BANES, Sally. Writing Dancing in the Age of Postmodernism. Estados Unidos: Wesleyan University Press, 1994.

BELÉM, Elisa. Modo de análise dos espetáculos: um olhar panorâmico. ILINX: Revista do LUME, Campinas, ano 6, v. 7, n. 6, ed. 6, p. 1-9, 2014. Disponível em: https://www.cocen.unicamp.br/revistadigital/index.php/lume.

BÍBLIA Sagrada: Edição de Promessas - Versão revista e corrigida na grafia simplificada, trad. João Ferreira de Almeida. São Paulo: King’s Cross Publicações, 2010.

CAMARGO, Roberto Gil. Função estética da luz. São Paulo: Perspectiva, 2012.

CARROL, Khadija Von Zinnenburg; PASQUINELLI, Matteo. Botanical drift: protagonists of the Invasive Herbarium. Berlin: Stenberg Press, 2018.

CHEVALIER, Jean; GHEERBRANT, Alain. Diccionario de los símbolos. Barcelona: Editorial Herder, 1986.

CURRIE, Gregory. An Antology of Art. Nova York: St. Martin's Press, 1989.

FEILER, Bruce. Adão e Eva, a primeira história de amor: e o que eles podem nos ensinar sobre relacionamentos. Rio de Janeiro: Zahar, 2019.

FORTIN, S.; GOSSELIN, P. Considerações metodológicas para a pesquisa em arte no meio acadêmico. ARJ - Art Research Journal/Revista de Pesquisa em Artes, v. 1, n. 1, p. 1-17, 4 maio 2014.

GALIZIA, Luiz Roberto. Os processos criativos de Robert Wilson: trabalhos de Arte Total para o Teatro Americano Contemporâneo. 2004. ed. São Paulo: Perspectiva, 2004. $207 \mathrm{p}$.

GEORGE, Jim. De Adão a Jesus - O perfil de 50 personagens que mudaram a História. Rio de Janeiro: Graça, 2012.

HEIDEGGER, Martin. Ser e Tempo. Rio de Janeiro: Editora Vozes, 2002.

HOLMBERG, Arthur. The Theatre of Robert Wilson (Directors in Perspective). Reino Unido: Cambridge University Press, 2005.

KRAUSE, Décio. Tópicos em ontologia analítica. São Paulo: Editora UNESP, 2017.

LANGER, Susanne. Sentimento e Forma: uma teoria da arte desenvolvida a partir de Filosofia em Nova Chave. São Paulo: Perspectiva, 2011. 
MANNHEIM, K. 1993. El problema de las generaciones, Revista Española de Investigaciones Sociológicas (REIS), n. 62, pp. 145-168. Nova York: Routledge \& Kegan Paul, 1952.

NISSA, Gregório de. A criação do homem - a Alma e a ressureição - a grande catequese. São Paulo: Editora Paulus, 2017.

PAVIS, Patrice. Dicionário de teatro. 3 ed. São Paulo: Perspectiva, 2008.

PINHEIRO, Lucas de Almeida. Bob Wilson: por trás do olhar de um surdo e da voz-pensamento de um autista $=$ Bob Wilson: behind a deaf's sight and an autistic's voicethought. 2017. 1 recurso online (220 p.). Dissertação (mestrado) - Universidade Estadual de Campinas, Instituto de Artes, Campinas, SP. Disponível em:

<http://www.repositorio.unicamp.br/handle/REPOSIP/325377>. Acesso em: 2 set. 2019.

SALLES, Cecília. Gesto inacabado: Processo de criação artística. São Paulo: FAPESP, 2006.

WOLFF, Christoph; EMERY, Walter. Bach, Johann Sebastian. Grove Music Online. 2001. https://

www.oxfordmusiconline.com/grovemusic/view/10.1093/gmo/9781561592630.001.0001/ omo-9781561592630-e-6002278195. Acesso em 21 jul. 2020. 